\title{
Post-transplantation osteoporosis
}

\author{
Osteoporose pós-transplante
}

Carolina A. Moreira Kulak', Victória Z. Cochenski Borba',

Jaime Kulak Júnior ${ }^{2}$, Denise Jonhsson Campos ${ }^{3}$, Elizabeth Shane ${ }^{4}$

\section{SUMMARY}

Transplantation is an established therapy for many hematologic disorders as well as for endstage diseases of the kidney, lung, liver, heart among others. Osteoporosis and a high incidence of fragility fractures have emerged as a complication of organ transplantation. Many factors contribute to the pathogenesis of osteoporosis following organ transplantation. In addition, most patients have some form of bone disease prior to transplantation, which is usually related to adverse effects of end-stage organ failure on the skeleton. This chapter reviews the mechanisms of bone loss that occur both in the early and late post-transplant periods including the contribution of immunosuppressive agents as well as the specific features of bone loss after kidney, lung, liver, cardiac and bone marrow transplantation. Prevention and treatment for osteoporosis in the transplant recipient will also be addressed. Arq Bras Endocrinol Metab. 2010;54(2):143-9

Keywords

Secondary osteoporosis; transplantation; immunosuppressive agents; bone loss

Serviço de Endocrinologia e Metabologia, Hospital de Clínicas, Universidade Federal do Paraná (SEMPR/HCUFPR), Curitiba, PR, Brasil

${ }^{2}$ Departamento de Obstetrícia e Ginecologia, UFPR,

Curitiba, PR, Brasil

${ }^{3}$ Serviço de Transplante de Medula Óssea, HC-UFPR, Curitiba, PR, Brasil

${ }^{4}$ Departamento de Medicina, College of Physicians and Surgeons, Columbia University, Nova Iorque, Estados Unidos

\section{SUMÁRIO}

Transplante de órgãos ou medula óssea é uma terapia conhecida para muitas doenças hematológicas e para estágios finais de doenças renais, pulmonares, hepáticas, cardíacas, entre outras. A osteoporose e o aumento da prevalência de fraturas por fragilidade óssea têm se mostrado como uma complicação do transplante. Muitos fatores contribuem para a patogênese da osteoporose relacionada ao transplante. Além disso, a maioria dos pacientes apresenta doença óssea antes do transplante, a qual é secundária à doença grave de base. Este artigo revisa os mecanismos da perda óssea que ocorrem tanto na fase precoce quanto na fase tardia após o transplante, incluindo o uso das drogas imunossupressoras, como também os fatores específicos envolvidos na perda óssea relacionados ao transplante renal, pulmonar, hepático, cardíaco e de medula óssea. A prevenção e o tratamento da osteoporose após transplante também são abordados nesta revisão. Arq Bras Endocrinol Metab. 2010;54(2):143-9

Descritores

Osteoporose secundária; transplante; drogas imunossupressoras; perda óssea

Correspondence to: Carolina A. Moreira Kulak Serviço de Endocrinologia e Metabologia, HC-UFPR Av. Agostinho Leão Júnior, 285 80030-013 - Curitiba, PR, Brasil kulakjc@uol.com.br

Received on Dec/3/2009 Accepted on Feb/9/2010

\section{INTRODUCTION}

$\mathrm{W}$ ithin the past two decades organ transplantation has become established as an important treatment option for several end-stage diseases of the kidney, heart, lung, liver and for many hematological disorders. The number of organs transplanted has increased along with the survival of transplant recipients. This has resulted in increase of recognition of long-term complications of transplantation such as osteoporosis and fractures (1-3). Low bone mass and fractures may antedate transplantation, related to traditional risk factors for osteoporo- sis, effects of chronic illness, and end-stage organ failure and its therapy on the skeleton (Table 1). Bone loss after transplantation is related to adverse effects of immunosuppressive drugs (glucocorticoids and calcineurin inhibitors) on bone remodeling (Figure 1). In this chapter, we will review the general mechanisms of bone loss after organ transplantation as well as the specific features relevant to each organ such as kidney, lung, liver, heart and bone marrow. In addition, we will address the therapeutic measures recommended for the prevention and treatment of osteoporosis after transplantation. 
Table 1. Specific factors that contribute to bone fragility before transplantation

\begin{tabular}{l}
\hline End-stage renal disease \\
\hline Renal osteodystrophy: \\
Secondary hyperparathyroidism \\
Adynamic bone disease \\
Osteomalacia \\
Mixed uremic disease \\
Metabolic acidosis \\
Hypogonadism \\
Long-term hemodialysis \\
Vitamin D deficiency \\
\hline End-stage lung disease \\
\hline Smoking \\
Glucocorticoid \\
Hypercapnia \\
Hypoxia \\
Hypogonadism and pancreatic insufficiency (cystic fibrosis) \\
\hline End-stage liver disease \\
\hline Alcohol abuse \\
Low body weight \\
Vitamin D deficiency and secondary hyperparathyroidism \\
Cholestasis \\
Hypogonadism \\
\hline Heart failure \\
\hline Exposure to loop diuretics \\
Exposure to heparin \\
Vitamin D deficiency and secondary hyperparathyroidism \\
Mild renal insufficiency \\
\hline Bone marrow transplant recipients \\
\hline Glucocorticoids \\
Chemotherapy \\
Hypogonadism \\
\hline
\end{tabular}

\section{SKELETAL EFFECTS OF IMMUNOSUPPRESSIVE DRUGS}

The natural history of post-transplantation osteoporosis suggests that there are two main phases, an early and a late phase; the difference between the two phases is mainly due to the doses of immunosuppressive drugs (2)

\section{GLUCOCORTICOIDS}

Glucocorticoids (GCs) are used in most immunosuppressive regimens after transplantation. Typically, in the early phase, which generally encompasses the first 6 weeks after transplantation, steroid doses are generally high (e.g., $30-50 \mathrm{mg} /$ day of prednisone or prednisolone at transplantation followed by rapid tapering to $5-10 \mathrm{mg}$ by 6 months). This causes marked suppression of osteoblast-mediated bone formation and inhibition

\section{A) EARLY POST-TRANSPLANTATION PERIOD}

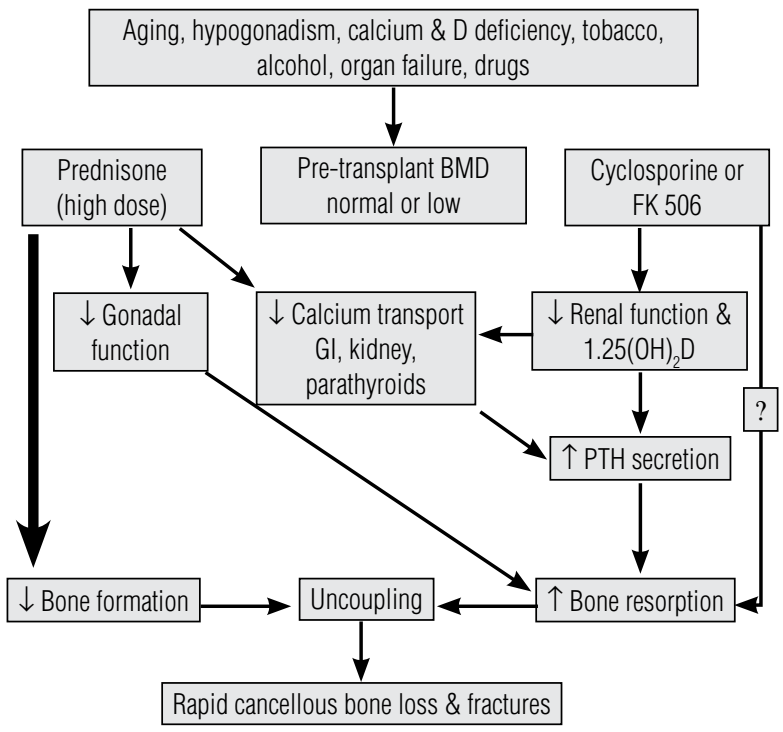

B) LATER POST-TRANSPLANTATION PERIOD

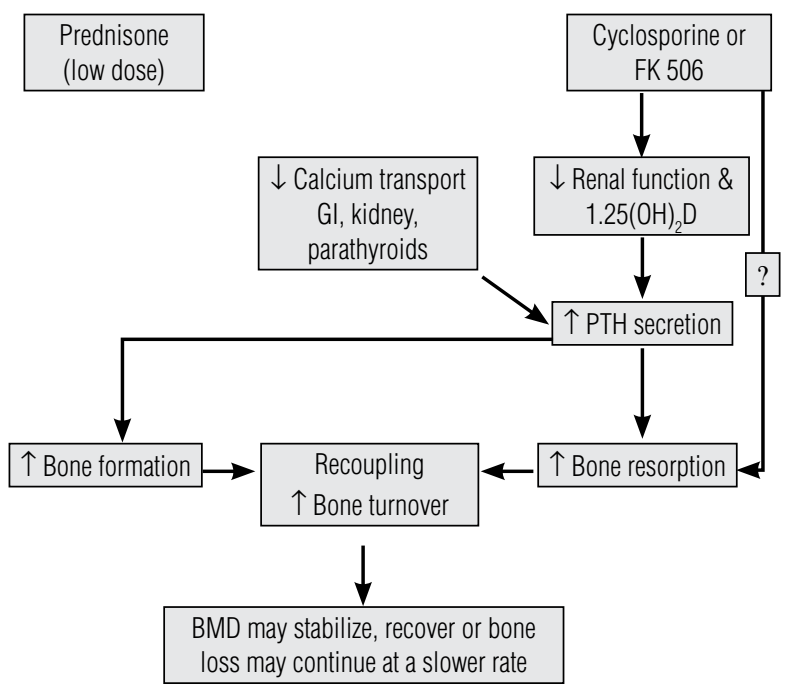

Figure 1. (A) Mechanisms of bone loss in the early phase of posttransplantation period. (B) Mechanisms of bone loss in the later phase of post-transplantation period.

With permission of Kulak CAM, Shane E. Transplantation osteoporosis: biochemical correlates of pathogenesis and treatment. In: Seibel MJ, Robbins SP, Bilezikian JP (eds). Dynamics of bone and cartilage metabolism, 2nd Edition. San Diego: Academic Press; 2006.

of osteoblast synthetic function (4). In comparison, direct effects of GCs on bone resorption are less prominent. However, GCs may increase resorption indirectly through reduction of intestinal and renal calcium absorption leading to a secondary hyperparathyroidism as well as inhibition of gonadal steroid synthesis. In addition, glucocorticoids stimulate osteoclastogenesis throughout the osteoprotegerin-RANK-L system (5). 


\section{CALCINEURIN INHIBITORS: CYCLOSPORINE A AND TACROLIMUS}

Cyclosporine A (CsA), small fungal cyclic peptide that inhibits the T-cell phosphatase calcineurin, decreases rejection episodes and therefore is very important in transplantation regimens (6). CsA may cause bone loss through direct effects on osteoclasts or acting indirectly on T-cell function. In addition, CsA may have independent effects on bone and mineral metabolism that contribute to post transplantation bone loss (7). However, studies evaluating the presence of bone loss secondary to CsA have conflicting results. One study on the kidney transplant recipient demonstrated that bone loss was associated with cumulative CsA dose and independent of the effects of GCs during the first two years after transplantation (8). In contrast, another study evaluating patients after renal transplantation who received CsA in a GC-free regimen did not show any bone loss (9). Tacrolimus (FK506), another calcineurin inhibitor, inhibits T-cell activation and proliferation and cytokine gene expression $(6,10)$. Although studies have demonstrated that FK506 leads to bone loss in rats, the skeletal effects in humans have not been thoroughly studied. Both liver and cardiac transplant recipients have been shown to sustain rapid bone loss with tracolimus (11). However, it is less intense than the bone loss seen with the use of CsA, probably due the fact that FK506 permits lower doses of GCs (10).

Later during the post-transplant period, when the GCs doses are tapered to below $5 \mathrm{mg}$ per day, there is recovery of osteoblast function and consequently an increase in bone formation and recoupling of the bone remodeling activity. However, both the direct and the indirect effects of cyclosporine and FK506 continue to influence the skeleton, resulting in secondary hyperparathyroidism and increased bone resorption. During this later phase, rates of bone loss slow down and there may even be some recovery, particularly at sites comprised predominantly of cancellous bone (2).

\section{KIDNEY TRANSPLANTATION}

Kidney transplantation is the treatment of choice for end-stage renal disease (ESRD). Restoration of renal function after kidney transplantation rectifies many of the disturbances that lead to renal osteodystrophy. There is resolution of hyperphosphatemia, an increase in serum $1,25(\mathrm{OH})_{2} \mathrm{D}$ levels and a rapid decline in the elevated levels of parathyroid hormone (PTH), al- though they may never completely normalize. In the first few months after kidney transplantation, PTH-dependent hypercalcemia and hypophosphatemia may develop. In addition, post-transplant hypophosphatemia may also be related to a primary defect in renal phosphate handling due to increased serum concentrations of circulating factors (12).

Bone loss rates are greatest in the first 6-18 months after kidney transplantation and range from $5 \%$ to $8 \%$ at the hip and $4 \%$ to $9 \%$ at the lumbar spine (13). Although low estradiol and testosterone levels have been associated with accelerated bone loss (14), bone loss has not been consistently related to gender, patient age, cumulative GC dose, rejection episodes, activity level, or PTH levels.

Fracture prevalence varies from $7 \%$ to $11 \%$ in nondiabetic renal transplant recipients, but is considerably higher in patients transplanted because of diabetic nephropathy and in those who receive kidney-pancreas transplants (15). Fractures occur relatively late in the post-transplant period, usually within the first three years after transplantation, and more commonly involve appendicular sites (hips, long bones, ankles, feet) than the axial sites (spine and ribs) (16). A large study of ESRD patients demonstrated that kidney transplantation was associated with a $34 \%$ greater risk of hip fracture than continued dialysis (17).

\section{LUNG TRANSPLANTATION}

Prospective studies have also demonstrated changes in bone mass and fracture incidence in patients who have received lung transplant (18-20). Bone loss rates at the lumbar spine and femoral neck range from $2 \%$ to $5 \%$ in the first year after lung transplantation $(13,18)$. In addition, fracture rates are also high, ranging from $18 \%$ to $37 \%$ during the first year, even in those patients who received antireabsorptive therapy. Pre-transplantation lower bone mineral density (BMD) and longer prior glucocorticoid therapy were correlated to the incidence of fractures. Spira and cols. (19) evaluated BMD in 28 patients prior and 6 to 12 months post lung transplantation (19). All patients received calcium (1 g per day) and vitamin D (400 UI per day) after the transplantation. There was a $5 \%$ reduction in BMD of both lumbar spine and femur neck, which was associated with the cumulative steroid dose after transplantation. In addition, 18\% sustained osteoporotic fractures, despite vitamin D and calcium supplementation. 


\section{CARDIAC TRANSPLANTATION}

The most rapid rate of bone loss after cardiac transplantation also occurs during the first year. The hallmark of osteoporosis after cardiac transplantation is the high rate of bone loss. BMD decreases 3\% to $10 \%$ at the lumbar spine and $6 \%$ to $11 \%$ at the femoral neck and then seems to stabilize during the second year and may even increase after the third year. $(1,3)$.

Vertebral fractures have been reported to occur from $14 \%$ to $36 \%$ during the first post transplantation year and $22 \%$ to $35 \%$ of long-term cardiac transplant recipients $(21)$. Bone resorption markers are increased in the initial period after transplantation whereas bone formation marker (osteocalcin) is reduced (3). The increase of resorption may be associated with CsA-induced renal insufficiency and resultant secondary hyperparathyroidism. In general, bone formation markers return to normal by 6 to 12 months after cardiac transplantation. Serum osteoprotegerin declines during immunosuppressive therapy and accounted for $67 \%$ of the variance of lumbar spine bone density changes during the first 6 months post-transplantation (22).

\section{BONE MARROW TRANSPLANTATION}

Bone marrow transplant (BMT) recipients have many known risk factors for developing low BMD after transplantation (23). The pathogenesis of bone disease following BMT differs from other forms of post-transplantation osteoporosis; recipients are usually younger; the time from primary diagnosis to the BMT usually does not exceed 2 years; history of prolonged bed rest is uncommon.

The rate of bone loss increases during the first year following BMT from 2\% to $9 \%$ at the lumbar spine and $6 \%$ to $11 \%$ at the femoral neck. In a study of long term follow up of bone loss after BMT, Schulte and Beelen observed that lumbar spine BMD begins to recover after 12 months, returning to baseline at 48 months (24). High levels of bone marrow interleukin- 6 during the immediate post-BMT period were related to the bone loss. Chronic graft versus host disease (GVHD) affects 30\%$60 \%$ of patients after BMT and is treated with high doses of GC, which contributes to bone loss in BMT recipients (25). In addition, low BMD was associated with insulin resistance (26). A marked decline in serum levels of 1,25-dihydroxyvitamin D3 and 25-hydroxyvitamin D3 in the course of allogeneic BMT was observed (27). This may be explained by the fact that after BMT patients have low sun exposure to prevent GVHD. Further, a study evaluating children and adolescents after BMT reported low ingestion of calcium and vitamin $\mathrm{D}(28)$.

\section{LIVER TRANSPLANTATION}

Bone loss and increased risk for fracture are common complications after liver transplantation (29). The progression of bone loss is similar to that following lung and cardiac transplantation, being more severe in the first 6-12 months. In earlier studies, bone loss after liver transplantation was characterized by a marked decrease in lumbar spine BMD of $3.5 \%-24 \%$, primarily during the first 3-6 months. However, in more recent studies, rates of bone loss have been as low as $2.3 \%$ at femoral neck, or even absent (30). Fracture incidence is also at its highest in the 6-12 months following the transplantation, with rates ranging from $24 \%-65 \%$; ribs and vertebrae are the most common sites (13). In recent prospective studies, the risk of post-transplantation fractures was related to older age and pre-transplantation $\mathrm{BMD}$ at the LS and FN (31). In addition, pre-transplantation vertebral fractures also have been shown to predict post transplantation vertebral fractures. Bone turnover has been reported to be low in many patients with liver failure; however, there is conversion to a high turnover state after liver transplantation that persists afterward. The increase in turnover may result from resolution of cholestasis or hypogonadism, increased PTH secretion, or CsA or FK506 administration. Significant elevations in osteoprotegerin and RANK-L levels during the first 2 weeks after liver transplantation (32) provide further evidence of high bone turnover.

It is important to point out that many of these studies are older and were conducted in an era of higher GC doses than those which are used today and that more recent studies suggest lower rates of bone loss and fracture rates than those that were reported in the mid-1990s and early 2000s.

\section{PREVENTION AND MANAGEMENT OF TRANSPLANTATION OSTEOPOROSIS}

\section{Pre-transplantation measures}

All transplant candidates should be evaluated and treated before transplantation, as bone disease is common in patients awaiting organ transplantation. An evaluation of BMD and some parameters of bone and mineral metabolism should be performed prior to the organ 
transplantation. This pre-transplant evaluation could be helpful to select patients who would benefit from immediate therapy. For patients with end-stage renal disease, evaluation and treatment for renal osteodystrophy according to accepted guidelines is highly recommended (33). Furthermore, patients must be encouraged to modify lifestyle factors with adverse effects on the skeleton, such as immobilization, smoking and alcohol abuse. Factors such as hypogonadism, vitamin D deficiency and secondary hyperparathyroidism should be corrected. In addition, the dose of glucocorticoids should be minimized to the extent possible and the recommended daily allowance for calcium (1,000-1,500 $\mathrm{mg} /$ day) and vitamin D (400-800 IU/day) followed.

\section{Prevention of early and late post-transplantation bone loss}

It is well known that the rates of bone loss and fracture incidence are highest immediately following transplantation. Therefore, preventive and therapeutic measures should be instituted at that time and without delay.

\section{Active vitamin D metabolites}

Vitamin D metabolites influence post transplantation bone loss through several mechanisms: they reverse GC-induced decreases in intestinal calcium absorption, limit the resultant secondary hyperparathyroidism (SHPT), promote differentiation of osteoblast precursors into mature cells, and may potentiate the immunosuppressive activity of CsA (34). Calcidiol (25-OHD) and alfacalcidiol, protect against bone loss in heart transplantation patients (35) and renal transplant recipients (36). Calcitriol $\left(1,25(\mathrm{OH})_{2} \mathrm{D}\right)$ has been studied in recipients of heart, lung, and liver transplants, with somewhat conflicting results. Beneficial effects have been seen with the use of $0.5 \mu \mathrm{g} / \mathrm{d}$ or more. A randomized study of heart or lung transplant recipients who received placebo or calcitriol $(0.5-0.75 \mu \mathrm{g} / \mathrm{d})$ for either 12 or 24 months after transplantation found that LS bone loss did not differ between groups (37). Furthermore, in a study of long-term heart transplant recipients found no protective effect of the calcitriol on the skeleton (38). In addition, hypercalcemia and hypercalciuria, common side effects of vitamin D metabolites, may develop at any point during treatment. Frequent monitoring of urine and serum is required. In our opinion, active vitamin $\mathrm{D}$ metabolites should not be selected as first-line treatment because of their limited effectiveness and narrow therapeutic window.

\section{Gonadal hormone replacement}

Few studies have approached the proposal of hormone replacement therapy (HRT) for transplant recipients, although a recent study showed a protective effect on the skeleton (39). The use of HRT in premenopausal women who develop amenorrhea after transplant should be administered provided there are no contraindications.

\section{Bisphosphonates}

Studies using both intravenous and oral bisphosphonates have shown they are effective to prevent bone loss after transplantation (23,40-42). Alendronate has been studied in both immediate (43) and long-term (42) transplant recipients. A randomized trial comparing alendronate $(10 \mathrm{mg} / \mathrm{d})$ and calcitriol $(0.25 \mu \mathrm{g}$ twice daily) for 1 year in patients directly after cardiac transplantation found that both regimens prevented bone loss at the LS and hip when compared with reference subjects who received only calcium and vitamin D (43). In the second year after cardiac transplantation, BMD remained stable, although alendronate and calcitriol were discontinued (44). Similarly, studies demonstrated the efficacy of intravenous ibandronate, zolendronic acid and of pamidronate in the prevention of bone loss after renal, heart, lung, liver and bone marrow transplant recipients, independent of the time following transplantation $(23,40,41,45,46)$.

A recent systematic review of 24 trials evaluated the benefits and risks of treatments used to reduce bone disease following kidney transplantation (47). Meta-analysis of all available such trials combined, however, shows that any intervention (bisphosphonate, vitamin D sterol, or calcitonin) for bone disease in kidney transplant recipients does reduce the risk of fractures. These agents also provide a significant improvement in bone mineral density when given after transplantation, although the clinical significance of this is uncertain due to the lack of validation of bone densitometry in chronic kidney disease. Regarding renal safety issues, the dose schedule is different for iv bisphosphonates. Infusion rate should be reduced to half the recommended rate in patients with glomerular filtration rate below $30 \mathrm{~mL} / \mathrm{min}$ or baseline creatinine below $2 \mathrm{mg} / \mathrm{dL}$ (48). 


\section{Teriparatide}

One double-blind, randomized trial, treated 26 kidney transplant recipients with administration of teriparatide (PTH 1-34) or placebo, and demonstrated that teriparatide does not improve BMD early after kidney transplantation (49). In addition, neither histological analysis nor bone markers provide evidence of improved bone turnover or mineralization.

\section{CONCLUSIONS}

Patients with end-stage organ failure and candidates for all types of transplantation have significant risk factors for osteoporosis and abnormal mineral metabolism before organ transplantation. Exposure to high doses of GCs and calcineurin inhibitors is associated with rapid bone loss and high fracture incidence immediately after transplantation. Effective therapies should incorporate pre-transplant measures to treat pre-existing bone diseases and also aggressive prevention of bone loss during the first 6 to 12 months after transplantation. The optimal dose, timing and frequency of administration of these therapies remains to be determined.

Of the presently available treatment modalities, bisphosphonates are the most consistently effective for both prevention and treatment of osteoporosis in transplant recipients. Use of new agents such as RANK-L antagonists and cathepsin $\mathrm{K}$ inhibitors in the management of osteoporosis after transplantation is lacking. Because the greatest amount of bone loss occurs during the first few months after transplantation, primary prevention therapy should commence immediately after surgery. However, the follow up of bone and mineral status of these patients should be maintained.

Acknowledgments: Elizabeth Shane has research support from Merck, Eli Lilly and Novartis.

Disclosure: no potential conflict of interest relevant to this article was reported.

\section{REFERENCES}

1. Cohen A, Shane E. Osteoporosis after solid organ and bone marrow transplantation. Osteoporos Int. 2003;14(8):617-30.

2. Kulak CA, Borba VZ, Kulak Junior J, Shane E. Transplantation osteoporosis. Arq Bras Endocrinol Metabol. 2006;50(4):783-92.

3. Stein E, Ebeling P, Shane E. Post-transplantation osteoporosis. Endocrinol Metab Clin North Am. 2007;36(4):937-63; viii.

4. Adachi JD. Glucocorticoid-induced osteoporosis. Osteoporos Int. 2009;20 Suppl 3:S239-40.
5. van Staa TP. The pathogenesis, epidemiology and management of glucocorticoid-induced osteoporosis. Calcif Tissue Int. 2006;79(3):129-37.

6. Epstein S. Post-transplantation bone disease: the role of immunosuppressive agents and the skeleton. J Bone Miner Res. 1996;11(1):1-7.

7. Sun L, Peng Y, Zaidi N, Zhu LL, lqbal J, Yamoah K, et al. Evidence that calcineurin is required for the genesis of bone-resorbing osteoclasts. Am J Physiol Renal Physiol. 2007;292(1):F285-91.

8. Josephson MA, Schumm LP, Chiu MY, Marshall C, Thistlethwaite JR, Sprague SM. Calcium and calcitriol prophylaxis attenuates posttransplant bone loss. Transplantation. 2004;78(8):1233-6.

9. Mclntyre HD, Menzies B, Rigby R, Perry-Keene DA, Hawley CM, Hardie IR. Long-term bone loss after renal transplantation: comparison of immunosuppressive regimens. Clin Transplant. 1995;9(1):20-4.

10. Goffin E, Devogelaer JP, Lalaoui A, Depresseux G, De Naeyer P, Squifflet JP, et al. Tacrolimus and low-dose steroid immunosuppression preserves bone mass after renal transplantation. Transpl Int. 2002;15(2-3):73-80.

11. Monegal A, Navasa M, Guanabens N, Peris P, Pons F, Martinez de Osaba MJ, et al. Bone mass and mineral metabolism in liver transplant patients treated with FK506 or cyclosporine A. Calcif Tissue Int. 2001;68(2):83-6.

12. Green J, Debby H, Lederer E, Levi M, Zajicek HK, Bick T. Evidence for a PTH-independent humoral mechanism in post-transplant hypophosphatemia and phosphaturia. Kidney Int. 2001;60(3):1182-96.

13. Ebeling PR. Approach to the patient with transplantation-related bone loss. J Clin Endocrinol Metab. 2009;94(5):1483-90.

14. Brandenburg VM, Ketteler M, Heussen N, Politt D, Frank RD, Westenfeld $\mathrm{R}$, et al. Lumbar bone mineral density in very long-term renal transplant recipients: impact of circulating sex hormones. Osteoporos Int. 2005;16(12):1611-20.

15. Nowacka-Cieciura E, CieciuraT, BaczkowskaT, Kozinska-Przybyl O, Tronina O, ChudzinskiW, et al. Bisphosphonates are effective prophylactic of early bone loss after renal transplantation. Transplant Proc. 2006;38(1):165-7.

16. Nisbeth $U$, Lindh E, Ljunghall S, Backman U, Fellstrom B. Increased fracture rate in diabetes mellitus and females after renal transplantation. Transplantation. 1999;67(9):1218-22.

17. Ball AM, Gillen DL, Sherrard D, Weiss NS, Emerson SS, Seliger $\mathrm{SL}$, et al. Risk of hip fracture among dialysis and renal transplant recipients. JAMA. 2002;288(23):3014-8.

18. Ferrari SL, Nicod LP, Hamacher J, Spiliopoulos A, Slosman DO, Rochat $\mathrm{T}$, et al. Osteoporosis in patients undergoing lung transplantation. Eur Respir J. 1996;9(11):2378-82.

19. Spira A, Gutierrez C, Chaparro C, Hutcheon MA, Chan CK. Osteoporosis and lung transplantation: a prospective study. Chest. 2000;117(2):476-81.

20. Shane E, Silverberg SJ, Donovan D, Papadopoulos A, Staron RB, Addesso $\mathrm{V}$, et al. Osteoporosis in lung transplantation candidates with end-stage pulmonary disease. Am J Med. 1996;101(3):262-9.

21. Shane E, Rivas M, Staron RB, Silverberg SJ, Seibel MJ, Kuiper J, et al. Fracture after cardiac transplantation: a prospective longitudinal study. J Clin Endocrinol Metab. 1996;81(5):1740-6.

22. Cohen A, Addonizio LJ, Lamour JM, Addesso V, Staron RB, Gao P, et al. Osteoporosis in adult survivors of adolescent cardiac transplantation may be related to hyperparathyroidism, mild renal insufficiency, and increased bone turnover. J Heart Lung Transplant. 2005;24(6):696-702.

23. D'Souza AB, Grigg AP, Szer J, Ebeling PR. Zoledronic acid prevents bone loss after allogeneic haemopoietic stem cell transplantation. Intern Med J. 2006;36(9):600-3. 
24. Schulte CM, Beelen DW. Bone loss following hematopoietic stem cell transplantation: a long-term follow-up. Blood. 2004;103(10):3635-43.

25. Lee WY, Kang MI, Oh ES, Oh KW, Han JH, Cha BY, et al. The role of cytokines in the changes in bone turnover following bone marrow transplantation. Osteoporos Int. 2002;13(1):62-8.

26. Faulhaber GA, Premaor MO, Moser Filho HL, Silla LM, Furlanetto TW. Low bone mineral density is associated with insulin resistance in bone marrow transplant subjects. Bone Marrow Transplant. 2009;43(12):953-7.

27. Kreutz M, Eissner G, Hahn J, Andreesen R, Drobnik W, Holler E. Variations in 1 alpha,25-dihydroxyvitamin D3 and 25-hydroxyvitamin D3 serum levels during allogeneic bone marrow transplantation. Bone Marrow Transplant. 2004;33(8):871-3.

28. Campos DJ, Biagine GL, Borba VZ. Bone mineral density, lean body mass, calcium and vitamin $D$ intake in children and adolescents after hematopoietic stem cell transplantation. Biol Blood Marrow Transplant. 2009;15:79-80.

29. Compston JE. Osteoporosis after liver transplantation. Liver Transpl. 2003;9(4):321-30.

30. Ninkovic M, Love S, Tom BD, Bearcroft PW, Alexander GJ, Compston JE. Lack of effect of intravenous pamidronate on fracture incidence and bone mineral density after orthotopic liver transplantation. J Hepatol. 2002;37(1):93-100.

31. Monegal A, Navasa M, Guanabens N, Peris P, Pons F, Martinez de Osaba MJ, et al. Bone disease after liver transplantation: a long-term prospective study of bone mass changes, hormonal status and histomorphometric characteristics. Osteoporos Int. $2001 ; 12(6): 484-92$.

32. Fabrega E, Orive A, Garcia-Unzueta M, Amado JA, Casafont F, Pons-Romero F. Osteoprotegerin and receptor activator of nuclear factor-kappaB ligand system in the early post-operative period of liver transplantation. Clin Transplant. 2006;20(3):383-8.

33. KDIGO clinical practice guideline for the diagnosis, evaluation, prevention, and treatment of Chronic Kidney Disease-Mineral and Bone Disorder (CKD-MBD). Kidney Int Suppl. 2009;(113):S1-130.

34. Briffa NK, Keogh AM, Sambrook PN, Eisman JA. Reduction of immunosuppressant therapy requirement in heart transplantation by calcitriol. Transplantation. 2003;75(12):2133-4.

35. Cohen A, Sambrook P, Shane E. Management of bone loss after organ transplantation. J Bone Miner Res. 2004;19(12):1919-32.

36. El-Agroudy AE, El-Husseini AA, El-Sayed M, Mohsen T, Ghoneim MA. A prospective randomized study for prevention of postrenal transplantation bone loss. Kidney Int. 2005;67(5):2039-45.
37. Sambrook P, Henderson NK, Keogh A, MacDonald P, Glanville A, Spratt $P$, et al. Effect of calcitriol on bone loss after cardiac or lung transplantation. J Bone Miner Res. 2000;15(9):1818-24.

38. Stempfle HU, Werner C, Siebert U, Assum T, Wehr U, Rambeck WA, et al. The role of tacrolimus (FK506)-based immunosuppression on bone mineral density and bone turnover after cardiac transplantation: a prospective, longitudinal, randomized, doubleblind trial with calcitriol. Transplantation. 2002;73(4):547-52.

39. Isoniemi H, Appelberg J, Nilsson CG, Makela P, Risteli J, Hockerstedt K. Transdermal oestrogen therapy protects postmenopausal liver transplant women from osteoporosis. A 2-year follow-up study. J Hepatol. 2001;34(2):299-305.

40. Coco M, Glicklich D, Faugere MC, Burris L, Bognar I, Durkin P, et al. Prevention of bone loss in renal transplant recipients: a prospective, randomized trial of intravenous pamidronate. J Am Soc Nephrol. 2003;14(10):2669-76.

41. Crawford BA, Kam C, Pavlovic J, Byth K, Handelsman DJ, Angus $\mathrm{PW}$, et al. Zoledronic acid prevents bone loss after liver transplantation: a randomized, double-blind, placebo-controlled trial. Ann Intern Med. 2006;144(4):239-48.

42. Giannini S, D’Angelo A, Carraro G, Nobile M, Rigotti P, Bonfante L, et al. Alendronate prevents further bone loss in renal transplant recipients. J Bone Miner Res. 2001;16(11):2111-7.

43. Shane E, Addesso V, Namerow PB, McMahon DJ, Lo SH, Staron $\mathrm{RB}$, et al. Alendronate versus calcitriol for the prevention of bone loss after cardiac transplantation. N Engl J Med. 2004;350(8):767-76.

44. Cohen A, Addesso V, McMahon DJ, Staron RB, Namerow P, Maybaum $S$, et al. Discontinuing antiresorptive therapy one year after cardiac transplantation: effect on bone density and bone turnover. Transplantation. 2006;81(5):686-91.

45. Pennisi P, Trombetti A, Giostra E, Mentha G, Rizzoli R, Fiore CE. Pamidronate and osteoporosis prevention in liver transplant recipients. Rheumatol Int. 2007;27(3):251-6.

46. Krieg MA, Seydoux C, Sandini L, Goy JJ, Berguer DG, Thiebaud $D$, et al. Intravenous pamidronate as treatment for osteoporosis after heart transplantation: a prospective study. Osteoporos Int. 2001;12(2):112-6.

47. Palmer SC, McGregor DO, Strippoli GF. Interventions for preventing bone disease in kidney transplant recipients. Cochrane Database Syst Rev. 2007(3):CD005015.

48. Miller PD. Treatment of osteoporosis in chronic kidney disease and end-stage renal disease. Curr Osteoporos Rep. 2005;3(1):5-12.

49. Cejka D, Benesch T, Krestan C, Roschger P, Klaushofer K, Pietschmann $P$, et al. Effect of teriparatide on early bone loss after kidney transplantation. Am JTransplant. 2008;8(9):1864-70. 